Journal of The Electrochemical Society, 154 (10) C553-C557 (2007)

\title{
Controlled Electrochemical Dissolution of Anodic Aluminum Oxide for Preparation of Open-Through Pore Structures
}

\author{
Xiaowei Zhao, Seok-Kyoo Seo, Ung-Ju Lee, and Kun-Hong Lee ${ }^{\mathrm{Z}}$ \\ ${ }^{a}$ Department of Chemical Engineering, Computer and Electrical Engineering Division, Pohang University \\ of Science and Technology (POSTECH), Pohang, Gyeongbuk 790-784, Korea
}

\begin{abstract}
A simple electrochemical method is presented to remove the bottom barrier layer of anodic aluminum oxide (AAO). In this method, an electrolysis process was performed in neutral $\mathrm{KCl}$ solution with $\mathrm{AAO}$ as the cathode. By applying a suitable cathodic potential, electrolyte temperature, and electrolysis time, the bottom barrier layer can be selectively dissolved by the etching of $\mathrm{OH}^{-}$ ions without disrupting the porous alumina structure. The cathodic polarization behavior was studied to illustrate the electrochemical dissolution mechanism and its influence on the AAO/Al electrode. This study provides broader potential applications of AAO in the fields of electronics, magnetics, photocatalysis, microsensors, and so on.
\end{abstract}

(c) 2007 The Electrochemical Society. [DOI: 10.1149/1.2759780] All rights reserved.

Manuscript submitted April 16, 2007; revised manuscript received May 25, 2007. Available electronically July 31, 2007.

Porous anodic aluminum oxides (AAO) have been attracting considerable attention in both the scientific and the commercial fields as an indispensable part of nanotechnology. The hexagonally ordered arrays of nanopores with a uniform pore size adjusted from 10 to $300 \mathrm{~nm}$, high pore densities of $10^{8}-10^{11} / \mathrm{cm}^{2}$, and high aspect ratios are desirable features that are hardly achieved using conventional lithographic techniques. Many studies have demonstrated that $\mathrm{AAO}$ is an excellent template or mask material for the fabrication of one-dimensional nanostructures, ${ }^{1-4}$ two-dimensional patterns, ${ }^{5-7}$ as well as in the design of various AAO-based nanodevices. ${ }^{8,9}$ It has extensive applications in high-density magnetic recording media, biosensors, optical and electrical emitters, and so on. To use such an alumina template, the pores usually have to be filled with conducting, semiconducting, or biomolecular materials and integrated with circuit components. However, it is well known that there is a semispherical alumina barrier layer existing between the bottom of the pore and the base Al. Typically, this insulating barrier layer has a thickness of 2-100 nm. It can block the direct electrical and chemical contacts between the substance in the pore channel and the base conducting substrate. In spite of the wide range of promising applications of the AAO membranes, the practical application is now severely hampered by the problem of the barrier layer. Therefore, it is essential and urgent to develop low-cost and simple methods that yield well-fabricated AAO membranes with open-through pore structures.

In the conventional method, the barrier layer is removed by the chemical etching of the freestanding AAO membrane in a porewidening solution ( $5 \mathrm{wt} \% \mathrm{H}_{3} \mathrm{PO}_{4}$ ). This method has two major disadvantages. ( $i$ ) It is difficult to handle ultrathin and extremely brittle AAO membranes. (ii) Further, it is very difficult to transfer AAO membranes greater than a few square millimeters onto an appropriate substrate. Alternatively, some techniques such as the voltage drop or the constant-current-mode anodization were adopted under the condition of not stripping the AAO membranes. ${ }^{10-15}$ These techniques can only thin or penetrate the barrier layer, but they cannot completely remove it. Recently, Crouse et al. found that anodizing an $\mathrm{Al}$ foil deposited on a Si substrate showed an inverted barrier layer and this layer could be selectively removed by chemical etching. ${ }^{16,17}$ Subsequently, other authors have demonstrated that similar results could be achieved using $\mathrm{Au} / \mathrm{Si},{ }^{18} \mathrm{Ti} / \mathrm{Si}$, ${ }^{19-21}$ $\mathrm{Au} / \mathrm{Ti} / \mathrm{Si},{ }^{22}$ ITO glass, ${ }^{23,24}$ and $\mathrm{Ag}^{25}$ substrates. However, these anodizing processes still face some challenges: $(i)$ the additional metal layer (e.g., $\mathrm{Au}$ ) induces the $\mathrm{Al}-\mathrm{Au}$ intermetallic phase, resulting in a deleterious oxygen evolution reaction; (ii) poor mechanical stability and insufficient substrate adhesion; and (iii) an inevitable oxidation of the substrate materials and nonuniform removal of the oxidized

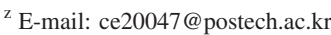

barrier layer. Such difficulties have compelled us to investigate alternative approaches to solve this problem.

Anodic oxide films exhibit the rectification effect. The anodic polarization of an $\mathrm{Al}$ electrode covered with oxide films induces small currents, while cathodic polarization results in large currents, which favor the dissolution of the oxide films. In previous research, the polarization of oxide films/Al electrodes toward more negative potentials has been studied, focusing chiefly on corrosion, electrolytic etching, and electrolytic coloring. ${ }^{26,27}$ More recently, Rabin et al. ${ }^{19}$ and Xu et al. ${ }^{28}$ have reported the removal of the barrier layers by cathodic polarization in a neutral $\mathrm{KCl}$ solution. Tian et al. ${ }^{21}$ have proposed the in situ penetration of the barrier layer by reversing the polarity of the voltage in the same electrolyte after Al sheet anodization. However, very little detailed study has been done in the past work to reveal the structure of the AAO membrane following cathodic polarization; therefore, there is a lack of knowledge concerning the mechanism of electrochemical dissolution of the barrier layer.

In this study, we investigate the cathodic polarization method in a neutral $\mathrm{KCl}$ solution allowing for the complete removal of the barrier layer and also discuss the influences of the cathodic polarization on the porous AAO structures and on the $\mathrm{Al}$ substrates. Through-hole AAO membranes have been fabricated on Al substrates as well as on $\mathrm{Nb} / \mathrm{SiO}_{x} / \mathrm{Si}$ substrates by applying a suitable reversed potential, electrolyte temperature, and electrolysis time. These through-hole membranes bear significant implication for catalysis and sensing applications.

\section{Experimental}

Two types of AAO membranes were prepared by using a twostep anodization procedure. ${ }^{29}$ The first type, bulk AAO, was fabricated using the direct anodization of a high-purity (99.999\%) bulk $\mathrm{Al}$ sheet. The second type, thin AAO, was fabricated by anodizing Al film deposited on a $\mathrm{Nb} / \mathrm{SiO}_{x} / \mathrm{Si}$ substrate. First, a $100 \mathrm{~nm}$ thick $\mathrm{Nb}$ film was deposited on a thermally oxidized 4 in. Si wafer by rf sputtering in a vacuum chamber. The $\mathrm{Al}$ thin film was subsequently thermally evaporated on top of the $\mathrm{Nb}$ layer with a thickness of $1.6 \mu \mathrm{m}$. The anodization was performed in a $0.3 \mathrm{M} \mathrm{H}_{2} \mathrm{C}_{2} \mathrm{O}_{4}$ solution at $40 \mathrm{~V}$ and $10^{\circ} \mathrm{C}$. The first anodization process was performed for $10 \mathrm{~h}$ for bulk AAO and $30 \mathrm{~min}$ for thin AAO. Then, the oxide film was dissolved in a mixture solution of 1.8 wt $\% \mathrm{H}_{2} \mathrm{CrO}_{4}$ and 7.4 wt $\% \mathrm{H}_{3} \mathrm{PO}_{4}$ at $65^{\circ} \mathrm{C}$. The second anodization process was performed from several minutes up to $6 \mathrm{~h}$ for different samples under the same condition. At the end of the second anodization process, the voltage was reduced stepwise from 40 to $15 \mathrm{~V}$ in decrements of $1 \mathrm{~V}$ per $9 \mathrm{~s}$, and then was maintained at $15 \mathrm{~V}$ for $15 \mathrm{~min}$. Cathodic polarization was performed in $0.5 \mathrm{M}$ neutral $\mathrm{KCl}$ solution with $\mathrm{AAO} / \mathrm{Al}$ as the cathode and a graphite plate as the anode. A cathodic potential from -4 to $-5 \mathrm{~V}$ was applied to the electrodes for different 


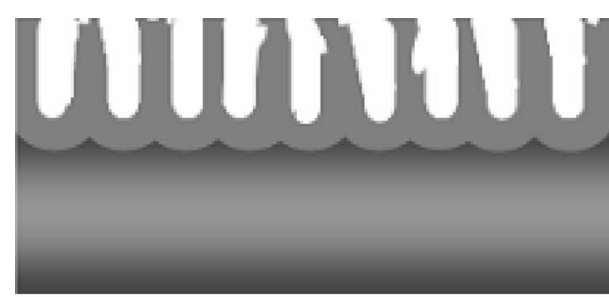

(a)

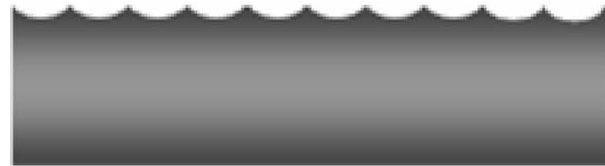

(b)

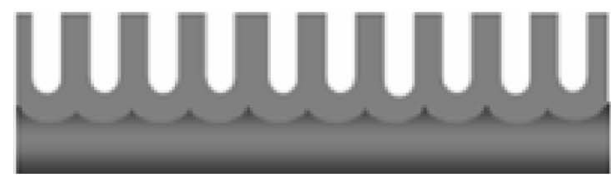

(c)

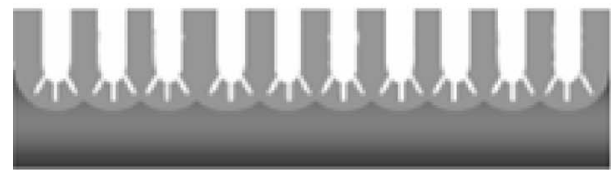

(d)

time according to samples. The porous structure of the AAO membrane was characterized by field-emission scanning electron microscope (FESEM) (Hitachi: S4300)

\section{Results and Discussion}

The general process employed for fabricating the open-through pore structure on an Al substrate is schematically shown in Fig. 1a-e. During the long first anodization period, the pores gradually self-adjusted to an ordered arrangement (Fig. 1a). After chemically etching the first anodized layer, an ordered nanoconcave pattern was left on the Al surface (Fig. 1b). The second anodization process was performed afterward, yielding ordered nanopore arrays (Fig. 1c). At the end of the second anodization step, a voltage-drop process was applied to partially penetrate the barrier layer (Fig. 1d). Finally, the AAO/Al electrode was cathodically polarized in the neutral $\mathrm{KCl}$ solution to dissolve the barrier layer (Fig. 1e). Figure 1f-h shows the representative SEM images of the AAO structure corresponding to those shown in Fig. 1c-e, respectively. The second anodization process was performed for $0.5 \mathrm{~h}$ and cathodic polarization for $900 \mathrm{~s}$ at $-5 \mathrm{~V}$ and $10^{\circ} \mathrm{C}$. The original pore diameter and the thickness of the barrier layer are both $\sim 40 \mathrm{~nm}$, as shown in Fig. 1f. After the voltage-drop process, some relatively fine-featured pathways partially penetrated into the barrier layer; however, a thin oxide layer still exists at the pore bottom, as shown in Fig. 1g. After the cathodic polarization process, the barrier layer at the pore bottom was completely dissolved and the AAO pores were directly open to the Al substrate. Note that the pore diameter was simultaneously widened to $\sim 60 \mathrm{~nm}$, as shown in Fig. $1 \mathrm{~h}$.

During cathodic polarization, the electrochemical process that occurs is shown in Fig. 2. $\mathrm{H}_{2} \mathrm{O}$ is decomposed into $\mathrm{H}^{+}$and $\mathrm{OH}^{-}$ions at the cathode. The $\mathrm{H}^{+}$ions rapidly pass through the bottom barrier layer through the localized conductive paths in the oxide, such as 


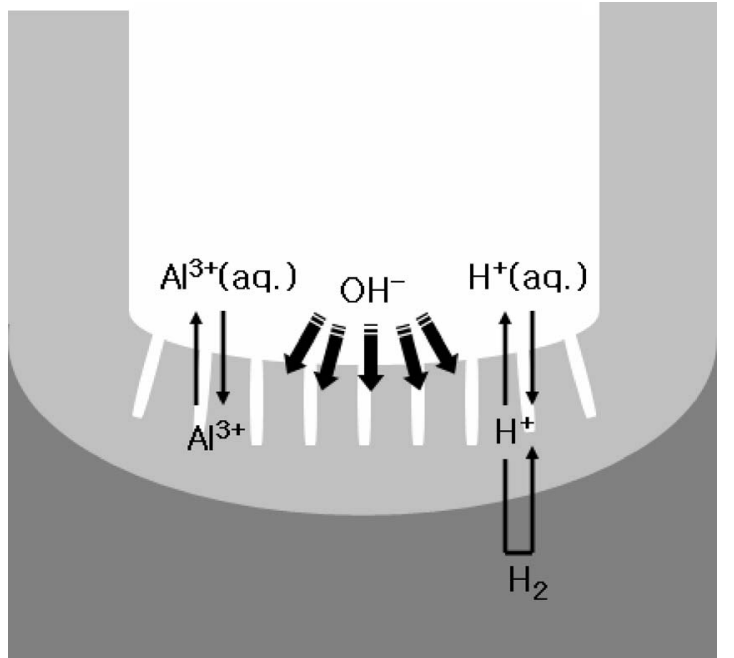

Figure 2. Schematic illustration of the electrochemical process during cathodic polarization.

microfissures. The $\mathrm{H}^{+}$ions capture the electrons and reduce to $\mathrm{H}_{2}$ at the cathode; then, they are immediately released from the surface of the AAO membrane. ${ }^{30,31}$ Therefore, $\mathrm{OH}^{-}$ions are generated at the bottom of every pore channel and are continuously transported toward the anode. During this period, a chemical attack by the $\mathrm{OH}^{-}$ ions can dissolve the alumina that constitutes the barrier layer as well as the pore wall due to the following reaction

$$
\begin{gathered}
\mathrm{Al}_{2} \mathrm{O}_{3}+2 \mathrm{OH}^{-} \rightarrow 2 \mathrm{AlO}_{2}^{-}+\mathrm{H}_{2} \mathrm{O} \\
\mathrm{H}^{+}+\mathrm{AlO}_{2}^{-}+\mathrm{H}_{2} \mathrm{O} \rightarrow \mathrm{Al}(\mathrm{OH})_{3}
\end{gathered}
$$

Therefore, we observed that the pore diameter also increased after the barrier layer was removed. During this reaction, more and more white floccules appeared in the $\mathrm{KCl}$ solution because of the formation of $\mathrm{Al}(\mathrm{OH})_{3}$.

We investigated three different thicknesses of the AAO membranes to clarify the reliability of removing the barrier layer by cathodic polarization. The second anodization of the $\mathrm{Al}$ sheets was carried out for $0.5,2$, and $6 \mathrm{~h}$. Under our experimental conditions, the growth rate of the AAO membrane was $61 \mathrm{~nm} / \mathrm{min}$ and the estimated thicknesses of the obtained AAO membranes were 1.83, 7.32 , and $21.96 \mu \mathrm{m}$. The cathodic polarization process was still performed in $0.5 \mathrm{M} \mathrm{KCl}$ solution at $-5 \mathrm{~V}$; the temperature was maintained at $0^{\circ} \mathrm{C}$ in order to prevent overetching of the AAO pore structure during the long electrolysis process. The cathodic polarization times were 1620,2100 , and $3900 \mathrm{~s}$ for these three membranes, respectively. The curves in Fig. 3 show the changes of the current with time. Initially, the current was recorded at the $5 \mathrm{~s}$ interval until $40 \mathrm{~s}$; then, it was recorded at the $20 \mathrm{~s}$ interval all the way to the end of the electrolysis process. During the cathodic polarization, the current mainly results from the reduction of the hydrogen ions to hydrogen gas. ${ }^{32}$ All the currents are obviously divided into three stages: from the start point up to the time points labeled as $a_{1}(20 \mathrm{~s})$, $b_{1}(270 \mathrm{~s})$, and $c_{1}(900 \mathrm{~s})$, the currents begin to increase unstably accompanied by gas evolution, indicating that the ions begin to be transported into the pores and the chemical reactions are initiated. After this induction period, the currents increase stably up to the time points labeled as $a_{2}(720 \mathrm{~s}), b_{2}(1020 \mathrm{~s})$, and $c_{2}(3230 \mathrm{~s})$. During this period, the barrier layer thins gradually. At last, the current slowly increases or reaches the saturated state. This indicates that some weak portions in the barrier layer have been completely dissolved preferentially. The $\mathrm{OH}^{-}$ions penetrate into the interface between the $\mathrm{AAO}$ and $\mathrm{Al}$ substrates and begin to corrode the $\mathrm{Al}$ surface. ${ }^{26,32-34}$ For a thicker membrane, a longer time is required to

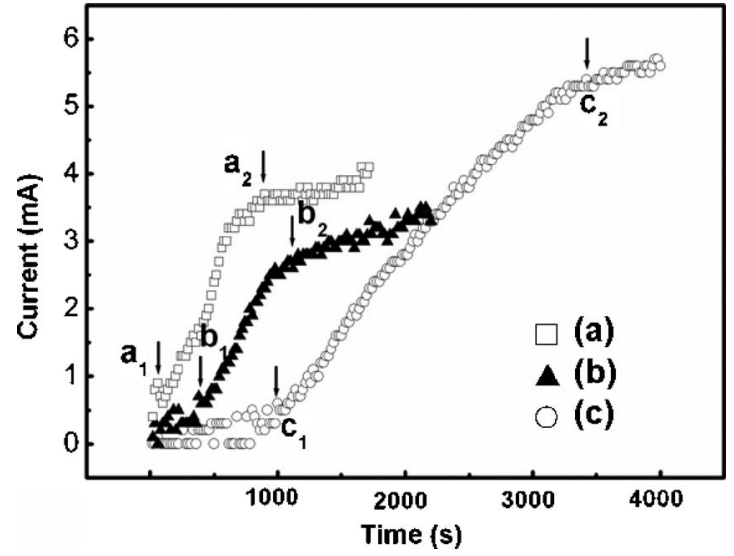

Figure 3. Changes of the currents with cathodic polarization time for three different thicknesses of AAO membranes. (a) AAO thickness: $1.83 \mu \mathrm{m}$, polarization time: $1620 \mathrm{~s}$, (b) AAO thickness: $7.32 \mu \mathrm{m}$, polarization time: $2100 \mathrm{~s}$, (c) AAO thickness: $21.96 \mu \mathrm{m}$, polarization time: $3900 \mathrm{~s}$.

overcome the induction period and reach the saturated state. This means that the cathodic polarization time for dissolving the barrier layer is dependent on the membrane thickness. This is because the porous layer contributes to the impedance value during the electrolysis process. According to our experimental results, it is difficult to remove the barrier layer for AAO membranes thicker than $\sim 20 \mu \mathrm{m}$, while the porous structure is well maintained. Because the etching of the alumina pore wall and barrier layer occurs simultaneously, a long cathodic polarization process dissolves the pore wall and damages the porous structure.

Figure $4 \mathrm{a}-\mathrm{c}$ shows the corresponding SEM images of the three AAO membranes (mentioned above) after cathodic polarization. Images on the left side are the top surfaces of AAO and the right sides are the corresponding cross-sectional pore channels. The AAO membranes with open-through pores were directly fabricated on the Al substrate. For $1.83 \mu \mathrm{m}$ thick AAO, the pore diameter was $\sim 68 \mathrm{~nm}$ after electrolysis for $1620 \mathrm{~s}$; for $7.32 \mu \mathrm{m}$ thick AAO, the pore diameter was $\sim 75 \mathrm{~nm}$ after electrolysis for $2100 \mathrm{~s}$; for $21.96 \mu \mathrm{m}$ thick AAO, the diameter was widened to $\sim 81 \mathrm{~nm}$ after electrolysis for $3900 \mathrm{~s}$; these phenomena are shown in Fig. 4a-c, respectively. Further, we also demonstrated the validity of removing the barrier layer of thin AAO membrane $(1 \mu \mathrm{m})$ formed on the $\mathrm{Nb} / \mathrm{SiO}_{x} / \mathrm{Si}$ substrate by using the above-mentioned method. Figure $4 \mathrm{~d}$ shows the SEM image of the thin AAO pore structure after cathodic polarization in $0.5 \mathrm{M} \mathrm{KCl}$ solution at $-4 \mathrm{~V}$ and $10^{\circ} \mathrm{C}$ for $900 \mathrm{~s}$. From the magnified inset image, we can observe the open pore bottom on the $\mathrm{Nb} / \mathrm{SiO}_{x} / \mathrm{Si}$ substrate.

After cathodic polarization electrolysis, we found that there were corrosive pits on the $\mathrm{Al}$ surface in some local areas; the AAO membrane was broken down from the Al substrate in these areas, as shown in Fig. 5a. The potential drops through the oxide and oxide/ solution interface were constant because the polarization of the cell was potentiostatic at all the points along the electrode surface. Hence, at microscopic irregularities and imperfections where the barrier layer was locally thinner than elsewhere, the magnitudes of both the electric field in the barrier layer and the interfacial potential drop were increased, and the dissolution occurred faster. Therefore, the barrier layer was preferentially penetrated in these local areas. The $\mathrm{Al}$ surface underneath began to be attacked by $\mathrm{OH}^{-}$ions, which corresponds to the slowly increased currents. The attacking of the $\mathrm{OH}^{-}$ions created corrosion pits on the $\mathrm{Al}$ surface. ${ }^{26,32-34}$ Furthermore, $\mathrm{Cl}^{-}$ions also played an important role in the process of pitting corrosion, which were selectively adsorbed on the crystal lattice of the hydrated oxide film by a complexation reaction with hydrated $\mathrm{Al}^{3+}$ ions ${ }^{35}$

$$
\mathrm{Al}^{3+}\left(\text { in } \mathrm{Al}_{2} \mathrm{O}_{3} \cdot n \mathrm{H}_{2} \mathrm{O} \text { crystal lattice }\right)+\mathrm{Cl}^{-} \rightarrow \mathrm{Al}(\mathrm{OH})_{2} \mathrm{Cl}
$$




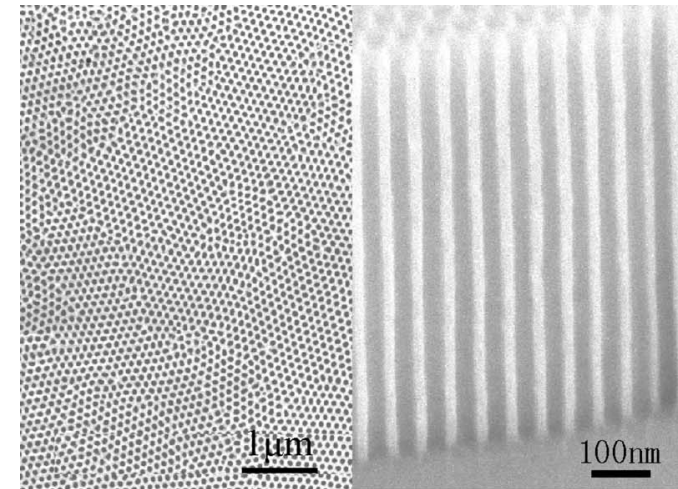

(a)

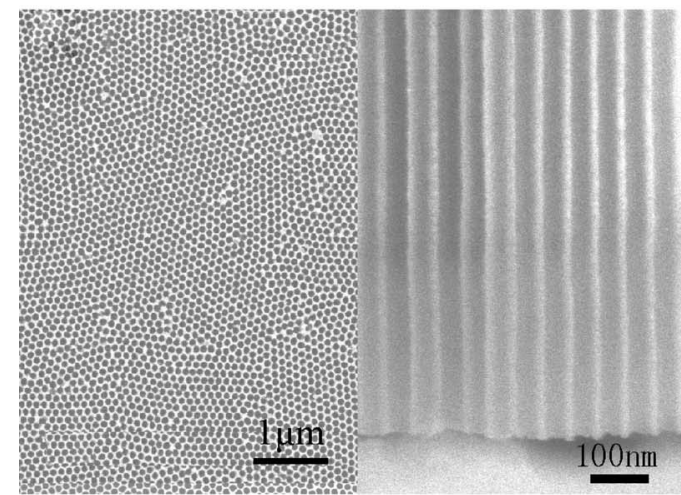

(b)

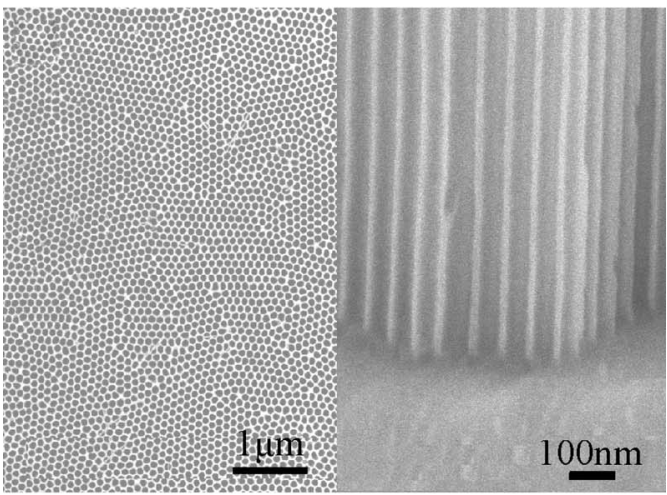

(c)

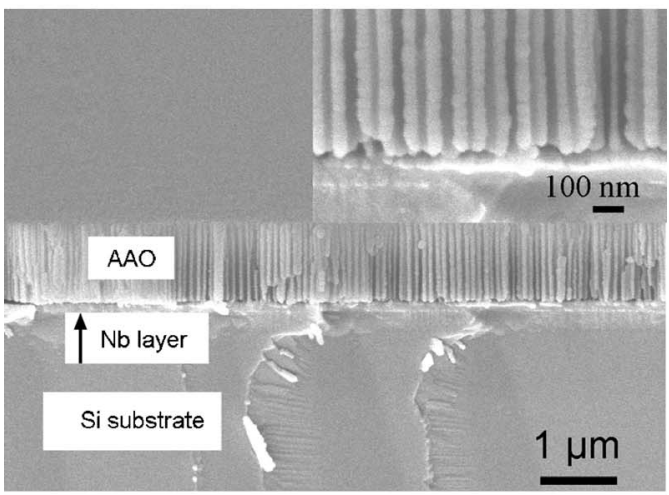

(d)

Figure 4. SEM images of AAO after cathodic polarization. (a)-(c) bulk AAO, cathodic polarization at $-5 \mathrm{~V}$ and $0{ }^{\circ} \mathrm{C}$. Left side: top surface; right side: cross section. (a) AAO thickness: $1.83 \mu \mathrm{m}$, polarization time: $1620 \mathrm{~s}$, (b) AAO thickness: $7.32 \mu \mathrm{m}$, polarization time: $2100 \mathrm{~s}$, (c) AAO thickness: $21.96 \mu \mathrm{m}$, polarization time: $3900 \mathrm{~s}$, (d) thin AAO, AAO thickness: $1 \mu \mathrm{m}$, cathodic polarization for $900 \mathrm{~s}$ at $-4 \mathrm{~V}$ and $10^{\circ} \mathrm{C}$.

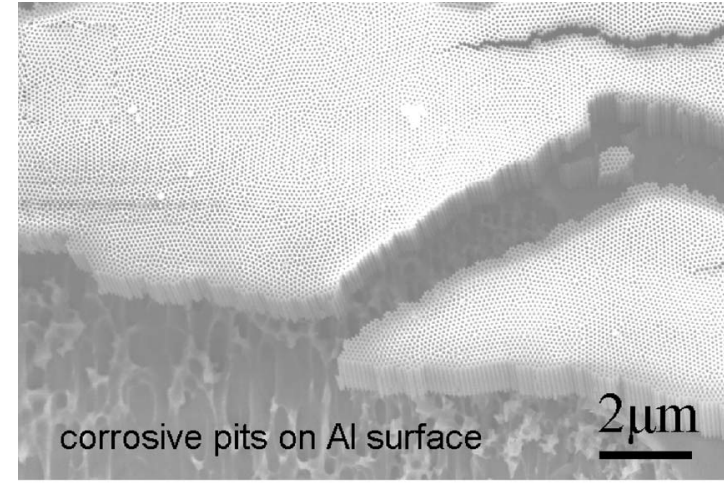

(a)

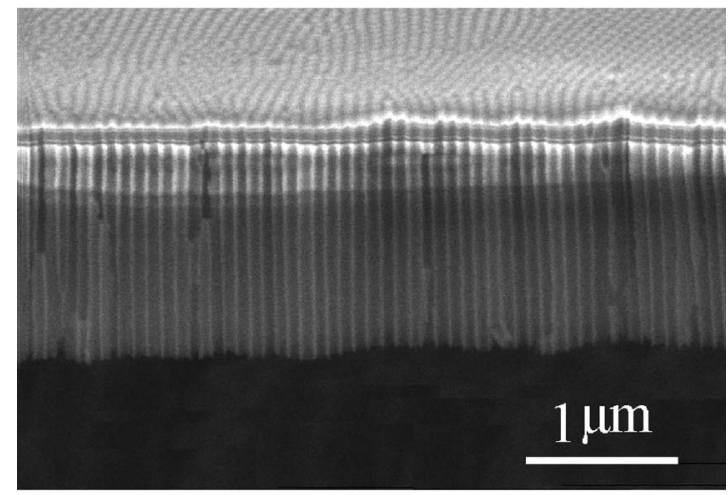

(b)

Figure 5. SEM images of the corrosive Al surface and the broken-down AAO membrane after cathodic polarization. AAO thickness: $1.83 \mu \mathrm{m}$, cathodic polarization: $900 \mathrm{~s}$ at $-5 \mathrm{~V}$ and $10^{\circ} \mathrm{C}$. (a) Corrosive pits on $\mathrm{Al}$ surface; the cracks were the result of bending of $\mathrm{Al}$ sheet in order to observe the cross section, (b) High magnification of the broken-down AAO membrane.

$$
\mathrm{Al}^{3+}+\mathrm{Cl}^{-}+2 \mathrm{H}_{2} \mathrm{O} \rightarrow \mathrm{Al}(\mathrm{OH})_{2} \mathrm{Cl}+2 \mathrm{H}^{+}
$$

The AAO membrane could be easily broken down from these corrosive pits due to hydrogen evolution. However, the porous structure of AAO was still maintained in a perfect state, as shown in Fig. 5b, and the bottom barrier layer was completely dissolved within a suitable electrolysis time.

\section{Conclusion}

To date, basic fabrication techniques of the AAO membranes have been well developed. Much interest is now focusing on the practical application of the AAO to various nanodevices with great industrial impact. As the barrier layer is the main roadblock for further investigation, it is necessary to develop convenient, inexpensive, and reliable methods for removing this layer of oxide, especially for handling ultrathin AAO membranes. Here, we have demonstrated the simple cathodic polarization electrolysis to remove the AAO barrier layer and realized the open-through pore structure on a bulk Al substrate and on a $\mathrm{Nb} / \mathrm{Si}$ substrate. During the cathodic polarization electrolysis, the barrier oxide was dissolved by $\mathrm{OH}^{-}$ ions generated at the pore bottom. This process also increased the pore diameter due to the chemical attack of the $\mathrm{OH}^{-}$ions on the alumina pore wall. Cathodic polarization for dissolving the barrier layer was dependent on the membrane thickness and proved to be more effective in the case of thin AAO membranes.

\section{Acknowledgments}

The authors thank the Ministry of Education of Korea for its financial support through the second phase BK21 program. This work was also supported by the Korea Foundation for International Cooperation of Science and Technology (KICOS) through a grant 
provided by the Korean Ministry of Science and Technology (MOST) in NANO/BIO/INFO Technology (NBIT) Symbiosis.

Pohang University of Science and Technology assisted in meeting the publication costs of this article.

\section{References}

1. J. Li, C. Papadopoulos, and J. M. Xu, Appl. Phys. Lett., 75, 367 (1999).

2. I. Lombardi, A. I. Hochbaum, P. D. Yang, C. Carraro, and R. Maboudian, Chem. Mater., 18, 988 (2006).

3. J. C. Bao, C. Y. Tie, Z. Xu, Z. Y. Suo, Q. F. Zhou, and J. M. Hong, Adv. Mater. (Weinheim, Ger.), 14, 1483 (2002).

4. M. Lahav, E. A. Weiss, Q. B. Xu, and G. M. Whitesides, Nano Lett., 6, 2166 (2006).

5. S. Zhao, H. Roberge, A. Yelon, and T. Veres, J. Am. Chem. Soc., 128, 12352 (2006).

6. H. Gao, N. N. Gosvami, J. Deng, Le-Shon Tan, and M. S. Sander, Langmuir, 22, 8087 (2006).

7. W. Lee, M. Alexe, K. Nielsh, and U. Gösele, Chem. Mater, 17, 3325 (2005).

8. S. K. Hwang, J. H. Lee, S. H. Jeong, P. S. Lee, and K. H. Lee, Nanotechnology, 16, 850 (2005)

9. Y. Kimura, H. Shiraki, K. Ishibashi, K. Miyamoto, and M. Niwano, in Pits and Pores III: Properties and Significance for Advanced Materials, P. Schmuki, D. J. Lockwood, Y. H. Ogata, M. Seo, and H. S. Isaacs, Editors, PV 2004-9, p. 273, The Electrochemical Society Proceedings Series, Pennington, NJ (2006).

10. R. C. Furneaux, W. R. Rigby, and A. P. Davidson, Nature (London), 337, 147 (1989).

11. M. Saito, M. Kirihara, T. Taniguchi, and M. Miyagi, Appl. Phys. Lett., 55, 607 (1989).

12. H. B. Xu, H. Z. Chen, W. J. Xu, and M. Wang, Chem. Phys. Lett., 412, 294 (2005).

13. S. K. Hwang, S. H. Jeong, O. J. Lee, and K. H. Lee, Microelectron. Eng., 77, 2
(2005)

14. K. Nielsch, F. Müller, A. P. Li, and U. Gösele, Adv. Mater. (Weinheim, Ger.), 12, $582(2000)$.

15. A. Saedi and M. Ghorbani, Mater. Chem. Phys., 91, 417 (2005).

16. D. Crouse, Y. H. Lo, A. E. Miller, and M. Crouse, Appl. Phys. Lett., 76, 49 (2000)

17. T. Shimizu, M. Nagayanagi, T. Ishida, O. Sakata, T. Oku, H. Sakaue, T. Takahagi, and S. Shingubara, Electrochem. Solid-State Lett., 9, J13 (2006).

18. Y. Yang, H. L. Chen, Y. F. Mei, J. B. Chen, X. L. Wu, and X. M. Bao, Solid State Commun., 123, 279 (2002)

19. O. Herz, P. R. Rabin, Y. M. Lin, A. I. Akinwande, S. B. Cronin, and M. S. Dresselhaus, Adv. Funct. Mater, 13, 631 (2003)

20. K. Kim, M. Kim, and S. M. Cho, Mater. Chem. Phys., 96, 278 (2006).

21. M. L. Tian, S. Y. Xu, J. G. Wang, N. Kumar, E. Wertz, Q. Li, P. M. Campbell, M. H. W. Chan, and T. E. Mallouk, Nano Lett., 5, 697 (2005).

22. M. S. Sander and L. S. Tan, Adv. Funct. Mater., 13, 393 (2003).

23. S. Z. Chu, K. Wada, S. Inoue, and S. Todoroki, J. Electrochem. Soc., 149, B321 (2002)

24. S. Z. Chu, K. Wada, S. Inoue, M. Isogai, Y. Katsuta, and A. Yasumori, J. Electrochem. Soc., 153, B384 (2006).

25. M. S. Sander, A. L. Prieto, R. Gronsky, T. Sands, and A. M. Stacy, Adv. Mater (Weinheim, Ger.), 14, 665 (2002).

26. J. Radošević, M. Kliškić, P. Dabić, R. Stevanović, and A. Despić, J. Electroanal. Chem. Interfacial Electrochem., 277, 105 (1990).

27. H. Takahashi, K. Kasahara, K. Fujiwara, and M. Seo, Corros. Sci, 36, 677 (1994).

28. G. R. Xu, F. L. Ren, S. H. Si, and Q. F. Yi, Acta Phys.-Chim. Sin., 22, 341 (2006)

29. H. Masuda and K. Fukuda, Science, 268, 1466 (1995).

30. C. F. Lin, M. D. Porter, and K. R. Hebert, J. Electrochem. Soc., 141, 96 (1994)

31. C. F. Lin and K. R. Hebert, J. Electrochem. Soc., 141, 104 (1994).

32. M. H. Wang and K. R. Hebert, J. Electrochem. Soc., 143, 2827 (1994).

33. E. P. G. T. van de Ven and H. Koelmans, J. Electrochem. Soc., 123, 143 (1976)

34. K. Nisancioglu and H. Holtan, Electrochim. Acta, 24, 1229 (1979).

35. C. H. Liang and W. Zhang, J. Chin. Chem. Soc. (Taipei), 53, 313 (2006) 